\title{
INDÍCES INADEQUADOS: REFLEXOS NOS BALANÇOS DAS EMPRESAS ESTRANGEIRAS $\left({ }^{*}\right)$
}

\author{
Ariovaldo dos Santos \\ Doutor em Ciências Contábeis pela FEA/USP
}

\section{INTRODUÇÃO}

É de conhecimento de todos que nem sempre os índices utilizados para reconhecimento dos efeitos da inflação, nas demonstrações contábeis, foram os mais adequados. Recentemente em 1990, tivemos outra vez, grande defasagem entre o índice utilizado para atualização das demonstrações contábeis e os que medem nossa variação de preços. Essas defasagens acabam por provocar, a curto, médio ou longo prazo, verdadeiras catástrofes nos resultados e conseqüentemente na situação patrimonial das empresas. Vamos avaliar como e quais conseqüências tais defasagens podem provocar nos Registros e nos resultados das empresas estrangeiras que escolheram o Brasil para realizar seus investimentos. Outro detalhe que estudaremos, está vinculado ao sistema de registro de capitais estrangeiros realizados pelo Banco Central do Brasil através do FIRCE - Departamento de Capitais Estrangeiros. O referido órgão não leva em consideração para seus registros, as variações da capacidade de compra da moeda dos países estrangeiros. Portanto, os investimentos efetuados em dólares americanos, não consideram a inflação nos Estados Unidos da América, da mesma forma que os investimentos em marcos alemães o consideram a inflação na Alemanha e assim por diante.

Sintetizando, podemos dizer que esse trabalho pretende explorar, mas não esgotar, dois aspectos que são os seguintes:

a) efeitos provocados pela utilização de índices defasados nas atualizações das demonstrações contábeis de empresas estrangeiras;

b) conseqüências da não utilização das variações do poder de compra das outras; moedas, para atualização dos investimentos e reinvestimentos realizados no Brasil.

A avaliação dos reflexos das defasagens de índices e do não reconhecimento da inflação externa nos balanços das empresas estrangeiras também serão apresentadas. Fizemos uma pesquisa onde conseguimos juntar um conjunto de balanços, de 49 empresas estrangeiras, relativas ao período 1978/1990. A perda de capacidade de compra de bens e serviços não é privilégio único e exclusivo de nossa moeda. As moedas estrangeiras, que são investidas em nosso país, também sofrem desvalorizações em seus respectivos países. Desta forma, entendemos que há necessidade de reconhecimento e controle da inflação externa nos registros dos capitais estrangeiros efetuados junto ao Banco Central.

( $^{*}$ Este trabalho constitui o resumo da tese apresentada originalmente a FEA-USP para obtenção do título de Doutor em Contabilidade.

\section{COMENTÁRIOS GERAIS}

Em resumo, toda a legislação relativa à movimentação de capitais estrangeiros no País está regulamentada, principalmente, na Lei no. 4.131, de 3 de setembro de 1962, e em algumas modificações que posteriormente foram efetuadas nessa Lei através da Lei no. 4.390, de 29 de agosto de 1964, pelo Decreto-Lei n0 2.073 de 20 de dezembro de 1983 e pela Lei n0 8.383 de 30 de dezembro de 1991.

Detalhes da Lei no. 41 31/62 que merecem ser destacados são os relativos aos artigos nos. 21 e 22 que estabelecem a obrigatoriedade da discriminação das parcelas do capital e dividendo ou lucros pertencentes às pessoas físicas ou jurídicas residentes, domiciliadas ou com sede no exterior.

A grande maioria das empresas estrangeiras toma essas disposições legais como se elas, simplesmente, não existissem. A discriminação da parcela de capital que pertence a estrangeiros foi, nos 49

Caderno de Estudos nº10, São Paulo, FIPECAFI, Maio/1994 
balanços pesquisados, em 1990, divulgados por apenas $61 \%$ das empresas. Algumas das empresas que hoje não divulgam essa informação já o fizeram no passado e outras nunca se preocuparam em fazê-lo.

Já a questão da divulgação da parcela de lucros e dividendos pertencentes a residentes e domiciliados no estrangeiro, foi encontrada em uma única empresa. Dentre os balanços por nós analisados, apenas uma empresa, a partir de 1988, passou a divulgar tal informação detalhando na demonstração das mutações do patrimônio líquido um item denominado "remessa de lucros".

Além da legislação citada anteriormente, o Banco Central do Brasil também tem competência para ditar normas relativas ao sistema de registro de capitais estrangeiros no Brasil. O FIRCE (Departamento de Capitais Estrangeiros do Banco Central do Brasil) tem a responsabilidade de controlar o investimento, o reinvestimento e fixar normas para a remessa de dividendos para o exterior, e esse trabalho tem sido desenvolvido ao longo dos anos de sua criação de forma bastante autônoma Essa autonomia, infelizmente, vez por outra, resultou em comunicados de sua emissão que não resistem à menor análise técnica e quer nos parecer, mesmo não sendo especialista em direito, que também não resistiriam a uma análise jurídica.

Uma das grandes questões relativas às demonstrações contábeis tem sido, sem nenhuma dúvida, a correção monetária do balanço. O tratamento dessa conta na demonstração de resultados tem provocado grandes discussões no que se refere ao seu entendimento, principalmente quando seu valor é credor. $O$ entendimento incorreto de que as contas do ativo permanente, apenas pela correção monetária, geram receitas e que as do patrimônio líquido geram despesas foi incorporado pelos técnicos daquele órgão. Não só este, mas o conceito das receitas financeiras, incluindo as variações monetárias nominais, também foi assumido.

Apesar dos inúmeros trabalhos publicados demonstrando o real significado da conta "Correção Monetária do Balanço", as empresas com saldo credor nessa conta encontravam sérias dificuldades para remeter os resultados realizados ou até para registrá-los como reinvestimento. O Banco Central do Brasil, através do FIRCE, sempre dificultou essa remessa ou o registro como reinvestimento.

Deve-se observar que esse procedimento esteve baseado na "pressuposição" de que a conta de correção monetária era a responsável pelo resultado positivo da empresa. Esse entendimento é totalmente equivocado e nos últimos tempos a divulgação da sistemática de correção monetária integral de balanços tem auxiliado no esclarecimento dessa questão. Atualmente o Banco Central reformulou esses conceitos, mas é bom ressalvar que para o período dos balanços incluídos na pesquisa (1978/1990) esse procedimento era o adotado.

\section{INFLAÇÃO VERSUS DESVALORIZAÇÃO CAMBIAL}

A inflação em níveis elevados acaba por provocar a completa destruição da utilidade real de troca que a moeda "deveria ter". Há uma constante modificação entre a possibilidade de troca de moedas por produtos e serviços que são oferecidos. Isso também é sentido na relação de troca entre as diversas moedas existentes. No início do século, o padrão ouro começou a desaparecer e, com o agravamento das variações nos níveis de preços provocados pela I Grande Guerra, o sistema de paridade até então vigente ficou ainda mais prejudicado.

A definição e fixação de taxa de câmbio têm sido muito discutidas entre os economistas de diversas correntes e nem sempre os resultados têm sido convergentes. Em 1919 o Prof. Gustav Cassel elaborou trabalho onde desenvolveu uma teoria que procurava correlacionar as variações de preços entre os países. Essa teoria tornou-se conhecida como Teoria da Paridade do Poder de Compra - PPP onde, em última análise, Cassel definia que a taxa cambial deve levar em consideração as variações relativas de preços em dois países considerados.

A paridade do poder de compra pode ser generalizada na seguinte expressão:

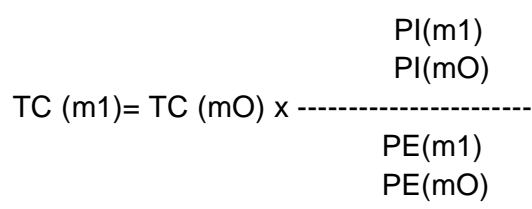

Onde, 
$\mathrm{TC}(\mathrm{m} 1)=$ Taxa de câmbio no momento 1

$\mathrm{TC}(\mathrm{m} 0)=$ Taxa de câmbio do momento $\mathrm{O}$

$\mathrm{PI}(\mathrm{m} 1)=$ Índice geral de preços internos no momento 1

$\mathrm{PI}(\mathrm{m} 0)=$ Índice geral de preços internos no momento $\mathrm{O}$

$\mathrm{PE}(\mathrm{m} 1)=$ Índice geral de preços externos no momento 1

$\mathrm{PE}(\mathrm{rn} 0)=$ Índice geral de preços externos no momento $\mathrm{O}$

Convém destacar que a Teoria da Paridade do Poder de Compra tem sofrido diversas críticas, porém a grande maioria dos economistas é unânime em reconhecer sua utilidade para países onde haja situações de inflação elevada ou a possibilidade de perturbações nos sistemas monetários, e esse é o caso brasileiro.

\section{ESCOLHA DO ÍNDICE}

Escolher o índice a ser utilizado na correção de demonstrações contábeis é, sem dúvida, uma das principais dificuldades que os profissionais da contabilidade têm encontrado. Aliás, é de se destacar que essa dificuldade não se apresenta apenas para nós, os contadores. Também os economistas encontram tal dificuldade, que pode ser justificada pela extrema complexidade encontrada para a escolha da solução.

$\mathrm{Na}$ página seguinte apresentamos tabelas anuais e acumuladas, de alguns dos índices que têm aceitação e amplitude nacionais que são o IGP da Fundação Getúlio Vargas e o INPC do Instituto Brasileiro de Geografia e Estatística. Além desses, incluímos nessas informações as variações das ORTNs, OTNs, BTNs e BTNFs que foram os índices utilizados oficialmente para a atualização das demonstrações contábeis no Brasil. Dois outros itens foram incluídos para efeito de comparação e utilização posterior nas simulações que serão efetuadas. São eles a inflação americana, medida pelo Consumer Price Index e o IGPD que representa o índice Geral de Preços Deslocado. Esse índice consta de trabalho que o Prof. Eliseu Martins realizou à época que prestava seus serviços ao Banco Central do Brasil e que me ofereceu para utilização, caso eu assim desejasse. Considero essa deslocação importante e dessa forma vou utilizá-la.

Em suma, a deslocação do IGP está baseada na hipótese de se estabelecer a efetiva variação de preços dentro do mês. Como se sabe, para cálculo do IGP os preços são coletados durante o mês e comparados com os preços coletados no mês anterior. Dessa forma, a média de preços de um mês é comparada com a média de preços do mês seguinte o que significa que a variação do índice considera os preços médios praticados durante o mês, e não o preço inicial e final de cada período.

O cálculo numérico do IGPD teve a seguinte metodologia. Tomou-se a raiz 30 do índice de um mês "M" e elevou-se o resultado a 15 encontrando-se um índice " $x$ " qualquer. Depois tomou-se a raiz 30 do índice do mês "M+1" e também elevou-se a 15 obtendo-se o índice "y". A multiplicação dos índices " $x$ " e "y" dá o índice mensal, medido do início ao final, relativo ao mês "M'. Esse cálculo foi repetido, mês a mês, para o período de janeiro de 1979 a dezembro de 1990.

As tabelas desses índices gerais de preços, comparados aos que foram utilizados para a correção das demonstrações contábeis, por si já dão a exata idéia de amplitude e quando aconteceram as maiores defasagens.

\section{VARIAÇÕES ANUAIS DOS ÍNDICES}

\begin{tabular}{|c|r|c|c|c|c|c|}
\hline Período & ORTN/BTN & INPC & IGP & IGPD & Câmbio & Infl.EUA \\
\hline 1979 & 47.19 & 70.79 & 77.30 & 79.44 & 102.52 & 13.30 \\
\hline 1980 & 50.78 & 99.70 & 110.24 & 110.57 & 54.01 & 12.40 \\
\hline 1981 & 95.57 & 93.51 & 95.19 & 94.93 & 95.10 & 8.90 \\
\hline 1982 & 97.76 & 100.31 & 99.72 & 102.30 & 97.71 & 3.90 \\
\hline 1983 & 156.58 & 177.97 & 211.00 & 212.10 & 289.44 & 3.80 \\
\hline 1984 & 215.28 & 209.12 & 223.81 & 227.95 & 223.58 & 4.00 \\
\hline 1985 & 219.37 & 239.05 & 235.11 & 242.69 & 229.46 & 3.80 \\
\hline 1986 & 69.09 & 59.20 & 65.03 & 60.94 & 42.41 & 1.10 \\
\hline 1987 & 338.02 & 394.60 & 415.83 & 432.04 & 383.64 & 4.40 \\
\hline 1988 & 816.06 & 993.29 & 1.037 .56 & 1.117 .81 & 959.22 & 4.40 \\
\hline
\end{tabular}

Caderno de Estudos nº10, São Paulo, FIPECAFI, Maio/1994 
Índices Inadequados: Reflexos nos Balanços das Empresas Estrangeiras 4

\begin{tabular}{|l|r|l|l|l|l|l|l|}
\hline 1989 & 1.481 .89 & 1.863 .53 & 1.782 .90 & 2.012 .68 & 1.384 .12 & 4.60 \\
\hline 1990 & 845.12 & 1.585 .20 & 1.476 .87 & 1.217 .45 & 1.399 .82 & 6.10 \\
\hline
\end{tabular}

(1) - Em 1979, 1ำ Trim. = IGP - Di (13,79\%) e depois INPC (50,90\%)

(2) - Consumer Prince Index

\section{VARIAÇÕES ACUMULADAS DOS ÍNDICES}

\begin{tabular}{|r|r|r|r|r|r|r|}
\hline Período & ORTN/BTN & $\begin{array}{r}\text { INPC } \\
(1)\end{array}$ & IGP & IGPD & Câmbio & $\begin{array}{r}\text { Infl.EUA } \\
(2)\end{array}$ \\
\hline 1978 & 1.00 & 1.00 & 1.00 & 1.00 & 1.00 & 1.0000 \\
\hline 1979 & 1.47 & 1.71 & 1.77 & 1.79 & 2.03 & 1.1330 \\
\hline 1980 & 2.22 & 3.41 & 3.73 & 3.78 & 3.12 & 1.2735 \\
\hline 1981 & 4.34 & 6.60 & 7.28 & 7.37 & 6.09 & 1.3868 \\
\hline 1982 & 8.58 & 13.22 & 14.53 & 14.90 & 12.03 & 1.4409 \\
\hline 1983 & 22.02 & 36.75 & 45.19 & 46.50 & 46.85 & 1.4957 \\
\hline 1984 & 69.44 & 113.60 & 146.34 & 152.51 & 151.61 & 1.5555 \\
\hline 1985 & 221.76 & 385.15 & 490.39 & 522.63 & 499.49 & 1.6146 \\
\hline 1986 & 374.97 & 613.17 & 809.29 & 841.12 & 711.33 & 1.6324 \\
\hline 1987 & 1.642 .43 & 3.032 .72 & 4.174 .56 & 4.475 .09 & 3.440 .25 & 1.7042 \\
\hline 1988 & 15.045 .68 & 33.156 .44 & 47.488 .13 & 54.498 .05 & 36.439 .85 & 1.7792 \\
\hline 1989 & 238.006 .13 & 651.036 .62 & 894.153 .96 & 1.151 .369 .44 & 540.811 .05 & 1.8610 \\
\hline 1990 & 2.249 .443 .52 & 10.971 .269 .18 & 14.099 .645 .49 & 15.168 .716 .66 & 8.111 .192 .27 & 1.9745 \\
\hline
\end{tabular}

(1) - Em 1979, 1ำ Trim. = IGP - Di (13,79\%) e depois INPC $(50,90 \%)$

(2) - Consumer Prince Index

\section{RESULTADOS DA PESQUISA}

\section{Introdução}

As informações desta pesquisa foram extraídas dos balanços publicados de 49 empresas estrangeiras. Não sabemos quantas eram as empresas estrangeiras sediadas no Brasil em dezembro de 1990 e tampouco em dezembro de 1978 (o Banco Central não divulga esta informação), porém a pesquisa da editora abril intitulada "Maiores e Melhores ", coordenada pelo Prof. Stephen Charles Kanitz, editada em agosto de 1990, apresenta entre as 500 maiores empresas privadas, por vendas, 147 estrangeiras. A seguir apresentamos quadro comparativo entre a quantidade de empresas incluídas naquela pesquisa e a nossa.

\section{Quadro Comparativo entre Empresas incluídas nas Maiores e Melhores e Nossa Pesquisa}

\begin{tabular}{|c|c|c|}
\hline Nacionalidade & Maiores & Nossa \\
& Melhores & 11 \\
\hline Alemã & 23 & 13 \\
Americana & 61 & - \\
Árabe & 1 & 1 \\
Argentina & 1 & 1 \\
Belga & 1 & 1 \\
Canadense & 2 & 1 \\
Finlandesa & 1 & \\
\hline
\end{tabular}

Caderno de Estudos nº10, São Paulo, FIPECAFI, Maio/1994 


\begin{tabular}{|c|c|c|}
\hline Francesa & 7 & 6 \\
Holandesa & 6 & - \\
Inglesa & 11 & 2 \\
Italiana & 10 & 5 \\
Japonesa & 8 & 1 \\
Sueca & 4 & 3 \\
Suíça & 11 & $\mathbf{4 9}$ \\
\hline Total & $\mathbf{1 4 7}$ & \\
\hline
\end{tabular}

No que se refere ao capital registrado no FIRCE, o quadro apresentado na seqüência da uma boa idéia de amostra utilizada em nossa pesquisa. Vamos tomar os dados do Banco Central em dezembro de 1978 e compará-los aos patrimônios líquidos apresentados nos balanços das empresas pesquisadas. Utilizaremos os valores em cruzeiro e, de forma simplista, sem considerar os seus diversos componentes, que podem ou não tem registro em dólares, faremos a tradução pela taxa de dólar vigente em 31 de dezembro de 1978.

\section{Quadro Comparativo entre Dados do Banco Central e Nossa Pesquisa}

\begin{tabular}{|c|c|c|c|}
\hline Países & $\begin{array}{c}\text { Capital } \\
\text { Registro FIRCE (a) }\end{array}$ & $\begin{array}{c}\text { Capital } \\
\text { Nossa Pesquisa (b) }\end{array}$ & b/a \\
\hline & & & \\
Alemanha & 2097 & 1.376 & $65 \%$ \\
EUA & 3.822 & 840 & $22 \%$ \\
Japão & 1.404 & 153 & $11 \%$ \\
Suíça & 1.628 & 111 & $7 \%$ \\
Outros & 4.046 & 2.165 & $45 \%$ \\
\hline Total & 13.741 & 4.645 & $34 \%$ \\
\hline
\end{tabular}

Ainda, considerando-se dados oficiais, fizemos a comparação entre os dividendos efetivamente remetidos para o exterior, segundo dados obtidos no balanço de pagamentos elaborado pelo 0 Banco Central do Brasil, e os dividendos declarados pelas empresas. No período 1979/1990 os dividendos declarados pelas empresas incluídas em nossa pesquisa representaram aproximadamente 1/3 dos dividendos remetidos.

\section{Análise dos dados do período 1979/1 990 (dólares)}

Os valores dos patrimônios líquidos em dólares foram apurados com a utilização dos valores agregados em cruzeiros constantes das demonstrações contábeis levantadas em dezembro. Para essa tradução utilizamos as taxas cambiais vigentes no final de cada exercício.

A utilização do dólar como única unidade de medida utilizada na tradução dos balanços para moeda estrangeira está relacionada a dois fatos importantíssimos para a decisão de utilização apenas da moeda americana. O primeiro está vinculado à possibilidade de o capital que ingressou ro Brasil não estar representado pela moeda de origem da empresa. Por exemplo, uma empresa de origem suíça pode se instalar no Brasil trazendo recursos em dólares, francos suíços, francos franceses, marcos alemães, pesos uruguaios etc. Esses recursos são registrados pela moeda efetivamente internalizada no País e não por aquela que poderia identificar a origem da empresa, e são controlados dentro dos padrões do chamado sigilo bancário, portanto sem divulgação pelo Banco Central. O segundo está vinculado á impossibilidade comparativa dos valores apurados nos balanços das empresas, em vista do Banco Central utilizar para suas publicações, como regra geral, apenas a moeda americana.

Dessa forma, a seguir apresentamos a demonstração das mutações do Patrimônio Líquido traduzido para a moeda americana, em um quadro resumo das 49 empresas estrangeiras incluídas em nossa pesquisa. 
Índices Inadequados: Reflexos nos Balanços das Empresas Estrangeiras 6

\section{MUTAÇÕES DO PATRIMÔNIO LÍQUIDO GERAL EMPRESAS: 49}

\begin{tabular}{|c|c|c|c|c|c|c|}
\hline Histórico & $\mathbf{1 9 7 9}$ & $\mathbf{1 9 8 0}$ & $\mathbf{1 9 8 1}$ & $\mathbf{1 9 8 2}$ & $\mathbf{1 9 8 3}$ & 1984 \\
\hline Patrim.Líq.inicial (2) & $4.645,363$ & & & & \\
\hline Patrim.Liq. final (2) & $3.730,563$ & $4.131,618$ & $4.472,004$ & $5.187,708$ & $3,900,648$ & $4,930,196$ \\
\hline Aumento de Capital (1) & 164.619 & 152,009 & 444,715 & 343,794 & 610,430 & $\underline{624,630}$ \\
\hline Divid. Propostos (2) & $-131,238$ & -69.809 & $-138,101$ & $-179,465$ & $-92,432$ & $-164,468$ \\
\hline Divid. Intermed. (1) & $-136,617$ & -128.841 & $-66,290$ & 124,728 & $-87,465$ & $-105,116$ \\
\hline Reserva Reavaliação (1) & 267,327 & -2.155 & $-6,865$ & 33,691 & 45,308 & $\underline{545,548}$ \\
\hline Imp .Renda/C.Social (2) & 244,338 & 316.542 & 287,818 & 294,668 & 179,814 & $\underline{229,169}$ \\
\hline Resultado Exercício (2) & 203,685 & 485.559 & 150,161 & 589,473 & 226,775 & 587366 \\
\hline Imp. Renda-I.I.I.. (2) & 0 & 0 & 0 & 0 & 0 & 0 \\
\hline
\end{tabular}

\begin{tabular}{|c|c|c|c|c|c|c|c|}
\hline Histórico & 1985 & 1986 & 1987 & 1988 & 1989 & 1990 & Acumulado \\
\hline Patrim..Liq. final (2) & $5,169,464$ & $\underline{6,964,372}$ & $6,418,896$ & $6,245,868$ & $7,873,169$ & $\underline{5.322,340}$ & \\
\hline Aumento de Capital (1) & $\underline{-62,812}$ & 79,239 & 71,023 & 118,822 & 292,696 & 554,037 & $3,393,204$ \\
\hline Divid. Propostos (2) & $-185,773$ & $-273,475$ & $-183,082$ & $\underline{-361,455}$ & $-387,065$ & $-106,881$ & $2,273,242$ \\
\hline Divid. Intermed. (1) & $-112,615$ & $-158,415$ & $-168,869$ & $-\underline{293,268}$ & $-339,518$ & $-495,093$ & $-2,216,835$ \\
\hline Reserva Reavaliação & 109,088 & 96,866 & $-35,505$ & 53,555 & 170,788 & $\underline{270,974}$ & $1.548,619$ \\
\hline Imp.Renda/C.Social (2) & 297,902 & 373,916 & 233,527 & 280,797 & 505,086 & 287,866 & $3,531,442$ \\
\hline Resultado Exercício (2) & 557,513 & 963,262 & 379,658 & $\underline{1,147,919}$ & $1,879,508$ & $-83,507$ & $7,087,374$ \\
\hline Imp. Renda - III (2) & 0 & 0 & 0 & 0 & $\begin{array}{c}-112.353 \\
0\end{array}$ & $-47,418$ & $-159,771$ \\
\hline
\end{tabular}

\section{Patrimônio Líquido Final (Agregado) traduzido em dólares}

em milhões

\begin{tabular}{|l|l|}
\hline Ano & U\$\$ \\
\hline
\end{tabular}

Caderno de Estudos nº10, São Paulo, FIPECAFI, Maio/1994 


\begin{tabular}{|l|l|}
\hline & \\
& \\
\hline & \\
1978 & 4.645 \\
1979 & 3.731 \\
1980 & 4.132 \\
1982 & 4.472 \\
1983 & 5.188 \\
1984 & 3.901 \\
1985 & 4.930 \\
1986 & 5.169 \\
1987 & 6.964 \\
1988 & 6.419 \\
1989 & 6.246 \\
1990 & 7.873 \\
1990 & 5.322 \\
\hline \multicolumn{1}{|c}{${ }^{*}$ ajustado pela correção com utilização ao IPC }
\end{tabular}

(*) ajustado pela correção com utilização ao IPC

A análise dos valores dos patrimônios líquidos em dólares nos mostra que há uma redução drástica na capacidade aquisitiva do patrimônio líquido escriturado, mesmo quando a unidade de medida é o dólar.

Os números demonstram isso de forma bastante clara. Se tomarmos o valor do patrimônio líquido das empresas, em dezembro de 1978, admitindo-se que todos os valores ali incluídos são conversíveis em dólares, teremos U\$ 4,6 bilhões. Se adicionarmos os acréscimos de capital de U\$\$ 3,4 bihões (veja quadro da página seguinte) ocorridos durante o período de 1979/1990, o patrimônio líquido escriturado dessas empresas, em dezembro de 1990, deveria ser igual a U\$\$ 8,0 bilhões. A tradução do patrimônio líquido das empresas, em dezembro de 1990, resulta em U\$\$ 5,3 bilhões; isso significa que, seria qualquer outra consideração, o valor final do patrimônio líquido escriturado em dólares é menor US $\$ 2,7$ bilhões.

O valor do patrimônio líquido ajustado pelo IPC, convertido para dólares totaliza US $\$ 12,1$ bilhões, portanto superior aos US\$ 8,0 bilhões citados, será melhor analisado mais adiante quando os investimentos serão atualizados pela inflação americana.

\section{Investimentos e Reinvestimentos do período 1979/1990}

A seguir apresentamos quadro resumo de investimentos e reinvestimentos realizados pelas 49 empresas incluídas em nossa pesquisa. Mais uma vez ressalvamos que as informações foram obtidas aos balanços publicados. portanto sem o nível de detalhes que seria desejável. Dessa forma, assumimos que os aumentos de capital (investimentos) foram distribuídos de forma homogênea durante e o período; portanto, para sua tradução foram utilizados os dólares médios respectivos.

Os reinvestimentos foram obtidos através da diminuição dos dividendos intermediários e propostos do lucro líquido, após a compensação de prejuízos acumulados anteriores, caso existissem. O resultado final dessa operação foi considerado como valor passível do registro junto ao Banco Central e foi traduzido pela taxa vigente ao final de cada período.

Vale destacar que os resultados de nossa pesquisa são apresentados comparativamente aos registros pelo Banco Central.

\section{Investimentos e Reinvestimentos realizados pelas empresas incluídas na pesquisa comparadas aos do Banco Central}

em milhões de U\$\$

Caderno de Estudos nº10, São Paulo, FIPECAFI, Maio/1994 


\begin{tabular}{|c|c|c|c|c|c|}
\hline \multicolumn{2}{|c|}{ Nossa pesquisa } & \multicolumn{2}{l|}{ Banco Central } \\
\hline Ano & Invest. & Reinvest. & Total & FIRCE & $\%$ \\
\hline 1978 & - & - & 4.645 & 13.740 & 33,8 \\
1979 & 165 & 150 & 4.960 & 15.963 & 31,1 \\
1980 & 152 & 441 & 5.553 & 17.480 & 31,8 \\
1981 & 445 & 307 & 6.305 & 23.928 & 26,3 \\
1982 & 344 & 323 & 6.972 & 26.602 & 26,2 \\
1983 & 610 & 154 & 7.736 & 28.264 & 27,4 \\
1984 & 625 & 239 & 8.600 & 29.962 & 28,7 \\
1985 & $(63)$ & 286 & 8.823 & 30.996 & 28,4 \\
1986 & 79 & 449 & 9.351 & 31.348 & 29,8 \\
1987 & 71 & 352 & 9.774 & 32.653 & 29,9 \\
1988 & 119 & 235 & 19.128 & 35.498 & 28,5 \\
1989 & 293 & 674 & 11.095 & 36.670 & 30,2 \\
1990 & 554 & $(90)$ & 11.559 & 37.143 & 31,1 \\
\hline Total & $\mathbf{3 . 3 9 4}$ & $\mathbf{3 . 5 2 0}$ & & & \\
\hline
\end{tabular}

Os dados anteriores dão a exata idéia do comportamento dos investimentos estrangeiros no Brasil efetuados através da remessa ou reinvestimentos de capitais de risco. O quadro comparativo de participação de empresas incluídas na pesquisa, os investimentos efetivamente registrados pelo Banco Central mostram que as tais empresas responsáveis, no período de dezembro de 1990, por aproximadamente $1 / 3$ dos capitais aqui investidos.

Ao longo do período analisado esses dados nos mostram de forma clara os diversos momentos políticos vividos e seus reflexos na economia de nosso País. Por exemplo, a mudança do governo militar para o governo de transição democrática criou um clima de incerteza política que acabou por interferir no comportamento dos agentes econômicos. Em 1985, ano da mudança, houve investimento negativo; isso significa que o volume de capitais remetidos ao exterior foi superior ao recebido a título de investimentos. Não resta dúvida que os atrasos, o suposto não pagamento da dívida externa e posteriormente a declaração oficial de moratória muito contribuíram para esse estado de coisas.

Em 1990 há uma informação que merece ser destacada, Os reinvestimentos foram negativos, e isso não significa dizer que as empresas tiveram diminuído seus capitais registrados junto ao Banco Central, mas sim que o total de lucros auferidos nesse ano foram inferiores aos dividendos efetivamente distribuídos. 1990 foi um ano de péssimos resultados quando as incertezas políticas e econômicas acabaram por interferir de forma negativa na vida das empresas.

Outra forma de se analisar os reais investimentos feitos no Brasil, no período 1978/1990, através de capitais de risco será considerar as taxas de inflação dos países que investem no Brasil. Como já afirmamos anteriormente por falta de divulgação de dados mais completos por parte do Banco Central, concentraremos nossa análise admitindo-se que todos os investimentos realizados no Brasil, independentemente de suas origens, sejam corrigidos pela variação do poder aquisitivo do dólar. Portanto, considerando-se a variação do dólar e que os acréscimos de capital ocorreram de forma homogênea durante o período, o quadro de investimentos estrangeiros no Brasil, levando-se em conta apenas às empresas incluídas na nossa pesquisa, seria o seguinte:

\section{Investimentos e Reinvestimentos atualizados pela inflação americana}

\begin{tabular}{|l|c|c|c|}
\hline Ano & Investimento & Reinvestimento & em milhões de US\$ ${ }^{*}$ ) \\
& & & Total \\
\hline 1978 & - & - & 9.172 \\
1979 & 306 & 261 & 9.739 \\
1980 & 250 & 484 & 10.673 \\
1981 & 661 & 443 & 11.771 \\
1982 & 480 & 203 & 12.694 \\
1983 & 820 & 303 & 13.717 \\
1984 & 809 & 350 & 14.829 \\
1985 & -78 & 543 & 15.101 \\
1986 & 96 & 408 & 15.740 \\
1987 & 84 & 261 & 16.232 \\
1988 & 135 & & 16.628 \\
\hline
\end{tabular}

Caderno de Estudos nº10, São Paulo, FIPECAFI, Maio/1994 


\begin{tabular}{|c|c|c|c|}
\hline $\begin{array}{l}1989 \\
1990\end{array}$ & $\begin{array}{l}318 \\
571\end{array}$ & $\begin{array}{l}715 \\
-90\end{array}$ & $\begin{array}{l}17.661 \\
18.142\end{array}$ \\
\hline Totais & 4.452 & 4.518 & \\
\hline
\end{tabular}

(*) Valores em moeda de dezembro de 1990, considerando-se a inflação americana

Esse quadro demonstra de forma inequívoca a real posição dos investimentos estrangeiros realizados no Brasil. Considerando-se apenas a inflação americana, para que esses investimentos tivessem a mesma capacidade de poder aquisitivo que tinham quando foram realizados, hoje deveriam totalizar U\$\$ 18.142 milhões. Se tomarmos o valor escriturado do patrimônio liquido agregado das empresas em dezembro de $1990 \mathrm{e}$ traduzi-lo em dólares encontraremos apenas US\$ 5.322 milhões, Considerando-se o valor do patrimônio líquido escriturado, após o ajuste determinado pela legislação fiscal, o valor dos investimentos estrangeiros para a amostra utilizada será de U\$\$12.118 milhões. Isso significa dizer que o ajuste determinado pela legislação fiscal ainda é insuficiente para equiparar os valores dos investimentos reconhecidos nos patrimônios líquidos das empresas no Brasil.

Outro dado deve ser observado na amostra utilizada, e está relacionado ao valor do investimento realizado utilizando-se como índice o IGPD. Sabemos que se o índice oficial utilizado para corrigir as demonstrações financeiras fosse o IGPD e não a ORTN/BTNF, os valores apresentados nas demonstrações de resultados seriam outros, e conseqüentemente o imposto de renda e os dividendos seriam diferentes. Mesmo assim, se tomarmos as alterações sofridas pelos patrimônios líquidos das empresas através de resultados não distribuídos, novos ingressos de capital e constituição de reservas, e atualizarmos esses valores para moeda de dezembro de 1990, utilizando-se o IGPD, encontraremos um valor em cruzeiros, que traduzidos para dólares, equivalerá a US\$21.201 milhões. Esse valor é 75\% superior ao valor encontrado após a correção, com utilização do IPC, estipulada pela legislação fiscal editada em 1991. Em outras palavras, as defasagens nos patrimônios líquidos escriturados das empresas que têm investimentos no Brasil estão refletidas nos nossos registros oficiais, que são elaborados pelo Banco Central, e nas empresas matrizes que nos últimos anos receberam capital em devolução e o registraram como resultado do exercício,

\section{Patrimônio líquido agregado versus investimentos atualizados pela inflação americana}

Como já foi demonstrado anteriormente, as diferenças entre os valores escriturados dos patrimônios líquidos das empresas incluídas na pesquisa, e os investimentos atualizados pelos índices de inflação americana são extremamente relevantes. O quadro seguinte demonstra essas defasagens.

Comparativo entre os valores dos Patrimônios Líquidos agregados escriturados e os investimentos e reinvestimentos atualizados pela inflação americana

em milhões de U\$\$

\begin{tabular}{|l|c|c|c|}
\hline Ano & $\begin{array}{c}\text { P.L. Agregado } \\
\text { Escriturado }\end{array}$ & $\begin{array}{c}\text { Investimento } \\
\text { Atualizado }\end{array}$ & $\%$ \\
\hline & 4.645 & 4.645 & - \\
1978 & 3.731 & 5.588 & 66.7 \\
1979 & 4.132 & 6.884 & 60.0 \\
1980 & 4.472 & 8.267 & 54.9 \\
1981 & 5.188 & 9.363 & 56.0 \\
1982 & 3.901 & 10.391 & 37.5 \\
1983 & 4.930 & 11.682 & 42.2 \\
1984 & 5.169 & 12.349 & 41.6 \\
1985 & 6.964 & 13.013 & 53.5 \\
1986 & 6.419 & 14.010 & 45.8 \\
1987 & \multicolumn{3}{|c}{} \\
\hline
\end{tabular}

Caderno de Estudos nº10, São Paulo, FIPECAFI, Maio/1994 
Índices Inadequados: Reflexos nos Balanços das Empresas Estrangeiras 10

\begin{tabular}{|l|c|c|l|}
\hline 1988 & 6.246 & 14.984 & 41.7 \\
1989 & 7.873 & 16.646 & 47.3 \\
1990 & 5.322 & 18.142 & 29.3 \\
1990 & $12.118\left(^{*}\right)$ & 18.142 & 66.8 \\
& & & \\
\hline
\end{tabular}

(*) Ajustado pela correção com utilização do IPC

O patrimônio líquido agregado foi calculado pela equivalência contábil e representa a diferença aritmética entre os valores de ativo e as dívidas registradas pelas empresas pesquisadas, traduzido em dólares pela taxa corrente vigente ao final de cada ano. 1978 por ser o primeiro ano não apresenta defasagem, porém deve-se ressalvar que isso não significa que essas diferenças inexistiam. As diferenças anteriores a 1978 não foram mensuradas por não dispormos de demonstrações contábeis adequadas que permitissem tal aferição.

Imposto de Renda pago e Dividendos Distribuídos versus Patrimônio Líquido Final

A tabela a seguir nos mostra os valores relativos ao imposto de renda pago e dividendo distribuídos no período 1979/1990, medidos em dólares de dezembro de 1990; isto significa que cada um dos valores foi atualizado levando-se em consideração a inflação norte-americana.

Imposto de Renda pago, dividendos distribuídos e resultado do período1979/1990 atualizados pela inflação americana

em milhares de U\$\$

de dezembro de 1.990 .

\begin{tabular}{|l|c|c|c|c|}
\hline Ano & $\begin{array}{l}\text { Dividendos } \\
\text { Propostos }\end{array}$ & $\begin{array}{l}\text { Dividendos } \\
\text { Intermediários }\end{array}$ & $\begin{array}{l}\text { Imposto de } \\
\text { Renda }\end{array}$ & $\begin{array}{l}\text { Resultado } \\
\text { Atualizado }\end{array}$ \\
\hline & & & & \\
1979 & 225.711 & 253.429 & 425.812 & 354.966 \\
1980 & 108.235 & 21.785 & 490.783 & 752.836 \\
1981 & 196.626 & 98.487 & 409.790 & 213.796 \\
1982 & 245.925 & 174.219 & 403.791 & 807.769 \\
1983 & 122.021 & 117.643 & 237.376 & 299.370 \\
1984 & 208.797 & 136.073 & 290.937 & 745.679 \\
1985 & 227.182 & 140.307 & 364.305 & 681.785 \\
1986 & 330.787 & 192.664 & 452.277 & 1.165 .132 \\
1987 & 212.120 & 199.911 & 270.566 & 439.875 \\
1988 & 401.131 & 332.543 & 311.620 & 1.273 .924 \\
1989 & 410.672 & 368.421 & 655.096 & 1.994 .137 \\
1990 & 106.881 & 509.970 & 335.284 & $(83.507)$ \\
& & & & \\
\hline Total & $\mathbf{2 . 7 9 9 . 0 8 9}$ & $\mathbf{2 . 7 3 5 . 4 5 2}$ & $\mathbf{4 . 6 4 7 . 6 3 7}$ & $\mathbf{8 . 6 4 5 . 7 6 0}$ \\
& & & & \\
\hline
\end{tabular}

Assim se tornarmos a fórmula:

$P L i+R P+A C-D D=P L f$

onde,

PLi = Patrimônio Líquido inicial

$\mathrm{RP}=$ Resultado do Período

Caderno de Estudos nº10, São Paulo, FIPECAFI, Maio/1994 


$$
\begin{aligned}
& A C=\text { Aumento de Capital } \\
& D D=\text { Dividendos Distribuídos } \\
& P L f=\text { Patrimônio Líquido final }
\end{aligned}
$$

Teremos (em dólares atualizados):

$$
\begin{aligned}
& 9.172+8646+4.452-5.534=\text { PLf } \\
& \text { PLf }=16.736
\end{aligned}
$$

Considerando-se a inflação americana, o patrimônio líquido final escriturado, medido em dólares de 1.990, deveria ser de U\$ 16.736 milhões. Isso significa que para as empresas terem exatamente o mesmo capital investido em dólares, adicionado aos resultados auferidos nas operações, o valor do patrimônio líquido escriturado em dezembro de 1990, deveria ser de U\$\$16.736 milhões. Porém, quando traduzimos o patrimônio líquido escriturado das empresas em dezembro de 1990, chegamos ao valor de US\$12.118 milhões. o que representa uma redução de $U \$ \$ 4.618$ milhões.

Algumas observações podem ser feitas em relação a essa redução do patrimônio líquido. Primeiramente, se esse investimento for liquidado e realizado exatamente pelo patrimônio líquido escriturado, poderemos concluir que os dividendos remetidos ao exterior não passaram de repatriação do capital. Em segundo lugar, se a realização do investimento for efetuada por valor abaixo do patrimônio líquido escriturado, teremos uma situação idêntica a anterior, ou seja, os dividendos remetidos referiam-se a devolução do capital e não distribuição de resultados. Nessas duas situações de repatriação de capital, dependendo das circunstâncias, poderemos ter tido tributação de imposto de renda sobre excesso de remessas e, portanto estaríamos tributando o capital aqui internalizado.

Numa terceira hipótese, a realização ao patrimônio líquido poderia ser efetuada por valor superior ao valor escriturado, e nesse caso, a diferença será tributada pelo imposto de renda na forma de resultado realizado. Claramente, a tributação sobre U\$\$ 4.618 estaria sendo efetuada sobre o capital e não sobre resultados realizados.

As conclusões anteriores relativas à distribuição de dividendos que não passam de repatriação de capital, pagamento de imposto de renda sobre capital investido e remetido ao exterior, disfarçado na forma de resultado realizado, pagamento de imposto de renda, contribuição social e imposto sobre lucro distribuído (ILL) sobre "resultados realizados" serão ainda mais afetados, se levarmos em conta que os registros do FIRCE, no Banco Central, são mantidos pelos seus valores históricos e sem qualquer atualização.

\section{Conclusões finais}

Demonstramos de forma aritmética que os capitais aqui aplicados foram sendo diminuídos através de pagamentos de impostos indevidos, ou da remessa de dividendos que não passavam de repatriação de capital.

O controle adequado dos capitais estrangeiros poderá, inclusive, auxiliar na apuração mais precisa da avaliação de desempenho das empresas. A remessa de resultados que não sejam reais acaba por prejudicar qualquer análise de desempenho que tenha por base os lucros alcançados. Esses lucros, remetidos em excesso hoje, representarão a perda de capital que só será sentida amanhã. Entendemos ser recomendável que os capitais aqui aplicados sejam adequadamente controlados, e isso significa que não podem continuar sendo controlados apenas pelos seus valores históricos. A perda de capacidade de poder de compra que as moedas aqui investidas têm nos seus respectivos países de origem, deveria ser utilizada para atualizar os investimentos aqui realizados.

Esse tipo de controle acabará por indicar a necessidade de as empresas matrizes modificarem as formas de registro de seus investimentos no exterior

Se o índice utilizado nas demonstrações contábeis, no período 1978/1990, fosse o IGPD o patrimônio líquido agregado dessas empresas deveria apresentar um valor escriturado de US $\$ 21,2$ bilhões. A comparação desse valor com o patrimônio líquido ajustado pelo IPC em 1990 apresenta uma variação de aproximadamente $75 \%$.

Não há dúvidas que as diferenças apontadas acabaram por interferir nos valores relativos ao imposto de

Caderno de Estudos nº10, São Paulo, FIPECAFI, Maio/1994 
Índices Inadequados: Reflexos nos Balanços das Empresas Estrangeiras 12

renda devidos e dividendos distribuídos aos acionistas. Tivemos oportunidade de exemplificar como e porque as remessas de lucros e dividendos podem ser consideradas como repatriação de capital; também ficou evidente que o Poder Executivo transformou o índice oficial, aplicado na correção das demonstrações contábeis, num excelente instrumento de política fiscal, aumentando a arrecadação de impostos de forma expressiva, através da tributação de resultados fictícios auferidos pelas empresas. 
Índices Inadequados: Reflexos nos Balanços das Empresas Estrangeiras 13

\section{BIBLIOGRAFIA}

FIPECAFI/ARTHUR ANDERSEN - Normas e Práticas Contábeis no Brasil. - São Paulo, Editora Atlas, 1990.

HENDRIKSEN, Eldon S. - Accouting Theory - Irwin, Homewood, Illinois, 1982.

HICKS, James R. - Value and Capital - Oxford, 1946.

IUDICIBUS, Sérgio de; MARTINS, Eliseu e GELBCKE, Ernesto R. - Manual de Contabilidade das Sociedades por Ações. - Editora Atlas, 3a. Edição, São Paulo, 1990.

IUDICIBUS, Sérgio de - Teoria da Contabilidade - São Paulo, Atlas, 1980.

KANITZ, Stephen Charles - O País vem amortizando a dívida - Habitação e Poupança - ano 5, outubro/1 987.

KANITZ, Stephen Charles - A amortização secreta da dívida - Folha de São Paulo, 9 de dezembro de 1987.

KIRSTEN, José Tiacci - Metodologia da Construção de Índices de Preços ao Consumidor Custo de Vida - Tese de Doutoramento, FEA-USP, 1972.

MARTINS, Eliseu - Contribuição à Avaliação do Ativo Intangível - Tese de doutoramento São Paulo, FEA-USP, 1972.

MARTINS, Eliseu - Contabilidade Versus Fluxo de Caixa - São Paulo, Caderno de Temática Contábil e Balanço IOB nํ32, 1989.

SANTOS, Ariovaldo dos - Aspectos da Conversão de Demonstrações Financeiras para Moeda Estrangeira Dissertação de Mestrado, São Paulo, FEA-USP, 1980.

SZUSTER, Natan - Análise do Lucro Passível de Distribuição: Uma abordagem reconhecendo a manutenção do capital da empresa - Tese de Doutoramento, São Paulo, FEA-USP, 1.985.

ZINI, Álvaro Antônio Júnior - Taxa de Câmbio e Política Cambial no Brasil -Faculdade de Economia, Administração e Contabilidade - USP 1992 - São Paulo.

Caderno de Estudos nº10, São Paulo, FIPECAFI, Maio/1994 